\title{
O Processo de Compatibilização na Gestão de Projetos - Estudo de Caso
}

The process of compatibility in project management - Case Study

\begin{abstract}
Alisson Caetano da Silva ${ }^{1}$
Dione Luiza da Silva ${ }^{2}$ orcid.org/0000-0002-2101-4511

${ }^{1}$ Escola Politécnica de da Universidade de Pernambuco, Recife, Brasil,
${ }^{2}$ Escola Politécnica da Universidade de Pernambuco, Recife, Brasil,
${ }^{3}$ Escola Politécnica da Universidade de São Paulo, São Paulo, Brasil,
E-mail do autor principal: alissoncaetanodasilva@hotmail.com
\end{abstract}

orcid.org/0000-0003-4339-0961

Silvio Burrattino Melhado 3 (i) orcid.org/0000-0002-2295-6527

\section{Resumo}

A compatibilização de projetos compreende a atividade de sobrepor os vários projetos e identificar as interferências, bem como programar reuniões, entre os diversos projetistas e a coordenação, com o objetivo de resolver incompatibilizações que tenham sido detectadas. Baseado nessa definição, o objetivo do trabalho consiste em analisar o processo de compatibilização de projetos adotado por uma Empresa A de Infra Estrutura Urbana localizada na Região Metropolitana do Recife (RMR). A metodologia do trabalho foi realizada por meio da aplicação de questionários, com caráter de entrevista, direcionados aos gestores da empresa. Além disso, obteve-se acesso aos projetos elaborados pela empresa visando identificar a existência de incompatibilidades. De posse das respostas do questionário e do acesso aos projetos fornecidos pela empresa foi possível concluir que a Empresa A adota um método tradicional para compatibilização de projetos que é a sobreposição de layers. As incompatibilizações encontradas nos projetos fornecidos mostram que esse método é discutível.

Palavras-Chave: Compatibilização; Projetos; Empresa

\begin{abstract}
The compatibility of projects comprises the activity of superimposing the various projects and identify interference and schedule meetings between the various designers and coordination, in order to solve incompatibilizações have been detected. Based on this definition, the objective of this study is to analyze the process of project compliance adopted by the Company Infrastructure Urban located in the Metropolitan Region of Recife (RMR). The methodology of work was carried out through the use of questionnaires, interview with character, directed to the company's managers. In addition, it obtained access to projects developed by the company to identify incompatibilities. Armed with the answers of the questionnaire and access to projects provided by the company was concluded that the Company adopts the traditional method for compliance projects is that the overlapping layers. The incompatibilizações found in designs provided show that this method is questionable.
\end{abstract}

Key-words: Compatibility; Projects; Company 


\section{Introdução}

No Brasil, a maioria das empresas de projeto perdem muito na qualidade dos seus produtos por não investirem na compatibilização dos projetos. Usam o método tradicional de sobreposição de layers que acarreta, muitas vezes, em concepções errôneas e que podem gerar um custo elevado nas fases futuras, como atraso no cronograma e aumento do orçamento final da obra.

O processo de compatibilização em projetos de infraestrutura urbana é um grande desafio, por mobilizar inúmeros profissionais e diversas disciplinas como drenagem, estruturas, sinalização, acessibilidade, iluminação, geométrico e outros. Por isso, há necessidade de uma integração bem definida e que todas as etapas caminhem de forma sequencial e/ou pareada para que não haja nenhum projeto atropelando ou se prolongando a fase do outro.

Este trabalho discorre acerca de uma empresa de projetos de infraestrutura urbana e rodoviária, que atua no mercado há mais de 20 anos, prestando serviços para diversos órgãos públicos desde a esfera municipal até a federal. Porém, esta empresa é refém do retrabalho decorrente de falhas no processo de gestão de projetos, que gera atraso no cronograma e custos extras desde o material de impressão até a carga horária dos funcionários. Foi feita uma análise do modo de gestão de projetos da empresa, na qual mostrou-se os pontos positivos e negativos que ela apresenta no processo de compatibilização e, ao final, foram sugeridos métodos de melhoria para o processo utilizado, visando contribuir para a qualidade do seu produto final.

\section{Referencial teórico}

\subsection{Compatibilização de Projetos}

A compatibilidade é definida como atributo do projeto, cujos componentes dos sistemas, ocupam espaços que não conflitam entre si e, além disso, os dados compartilhados tenham consistência e confiabilidade até o final do processo de projeto e obra. Portanto, Segundo Graziano (2003), a compatibilização de projetos é uma atividade que torna os diferentes projetos compatíveis, proporcionando resultados integrados entre as diversas áreas que tornam uma construção real.
Conforme Picchi (1993), a compatibilização de projetos compreende a atividade de sobrepor os vários projetos e identificar as interferências, bem como programar reuniões, entre os diversos projetistas e a coordenação, com o objetivo de resolver interferências que tenham sido detectadas. Segundo Melhado (2005), na compatibilização, todos os projetos são sobrepostos para averiguar a intercessão entre eles, e os problemas são destacados para que a coordenação possa providenciar a melhor solução. $O$ autor defende ainda, que a compatibilização deve ocorrer quando os projetos já estão finalizados, trabalhando como uma "malha fina", na qual sejam detectados possíveis equívocos.

\subsection{Características Fundamentais de um bom Projeto}

Conforme Melhado (2006), na construção, os projetos de diferentes especialidades são geralmente desenvolvidos paralelamente pelos diversos projetistas (arquitetura, estruturas e sistemas prediais) em locais fisicamente distantes, sendo reunidos, muitas vezes, somente na hora da execução dos serviços. Este procedimento gera uma série de incompatibilidades e não permite clareza com relação às funções e responsabilidades dos profissionais envolvidos, comprometendo a qualidade do produto e causando enormes perdas de materiais e de produtividade. $\mathrm{O}$ autor ainda sintetiza as principais fases de execução do processo de projeto e seu interrelacionamento com o fluxo de informações durante seu desenvolvimento, conforme ilustra a Figura 1. Ele coloca a compatibilização como um item da validação, pois faz parte no processo de qualidade final do produto.

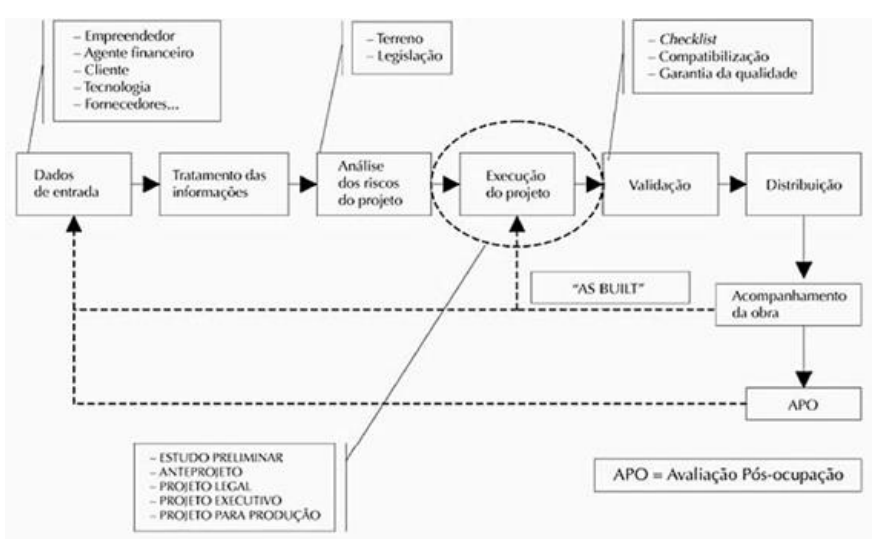

Figura 1: Processo de projetos x Fluxo de informações. 
Fonte: Melhado (2015).

O controle de qualidade deve ser feito por todos que participam da sua execução e dependendo da etapa da validação haverá modificações dos dados de entrada (MELHADO, 2006). A Figura 2 ilustra como deve ser feito o controle da qualidade nas etapas do processo de projeto.

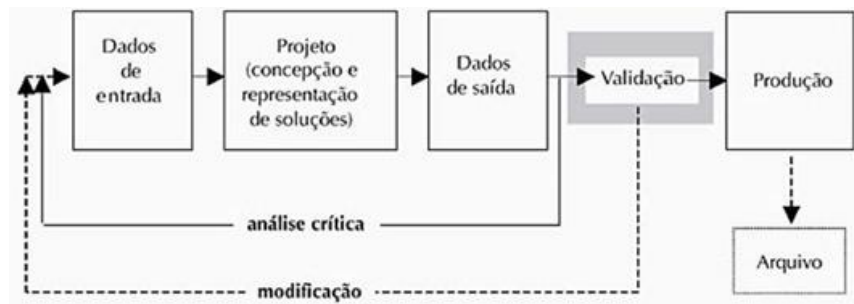

Figura 2: Controle de qualidade nas etapas do processo de projeto.

Fonte: Melhado (2006).

\section{Metodologia}

\subsection{Caracterização da empresa}

Foi realizado um estudo de caso em uma Empresa A de consultoria de infraestrutura urbana e rodoviária. A Empresa está há 20 anos no mercado, possui em média 200 funcionários e localiza-se na Região Metropolitana do Recife, prestando serviços para diversos órgãos públicos desde a esfera municipal até a federal. Este estudo de caso consistiu em identificar o processo de compatibilização de projetos realizado na referida empresa.

A Empresa A contrata seus projetos por meio de licitações considerando o menor preço, ou seja, o critério de seleção da proposta mais vantajosa para a Administração, basicamente, é estabelecido pelo licitante que apresentar a proposta que oferte o menor preço, e esteja de acordo com as especificações do edital ou convite.

Quando a licitação é consolidada, os projetistas realizam uma vistoria no local onde será executado o projeto, visando a solicitação dos serviços de topografia mais apropriados e demais serviços.

Na elaboração dos projetos, um gerente coordena todas as etapas envolvidas, ele é o responsável por determinar quais as disciplinas serão elaboradas em cada etapa, e estipula os prazos para que cada projetista envolvido esteja ciente do seu tempo.
A comunicação entre os diversos projetistas envolvidos é realizada por meio de reuniões formais e informais, e-mails e ligações telefônicas.

Os clientes participam integralmente de todas as fases do processo, estipulando os prazos para entrega de cada etapa dos projetos, analisando e criticando cada etapa e aprovando os projetos quando finalizados.

\subsection{Aplicação de questionários}

Para avaliar o processo de compatibilização de projetos na Empresa $A$, foi elaborado um questionário na plataforma do google forms, com caráter de entrevista, em que consta 8 questões abertas direcionadas para 2 gestores (Gestor 1 e 2) da empresa, estes são Engenheiros civis. O questionário foi enviado via email e abordou as seguintes questões:

1. Como é feito o processo de compatibilização na sua empresa?

2. Um dos motivos que levam à incompatibilidade nos projetos é a dificuldade de comunicação entre os agentes envolvidos neles, como é feita essa comunicação na sua empresa?

3. Como é feita a interação das diversas áreas envolvidas no projeto final?

4. Os prazos e o maior número de agentes envolvidos nos projetos dificultam a compatibilização de projetos. Na sua empresa como os prazos são distribuídos para que a compatibilização de projetos não seja prejudicada?

5. A tecnologia da informação tem ajudado os coordenadores a organizar dados, sobrepor os desenhos de arquitetura aos dos projetos de engenharia e compartilhar informações. Até que ponto a tecnologia tem beneficiado a compatibilização de projetos na sua empresa?

6. Na sua empresa se utiliza alguma ferramenta tecnológica para a compatibilização de projetos? Se sim, cite qual.

7. Se na sua empresa utilizar alguma ferramenta tecnológica para compatibilização de projetos, cite quais as vantagens que a ferramenta oferece para a qualidade da compatibilização de projetos.

8. Se na sua empresa utilizar alguma ferramenta tecnológica para compatibilização de projetos, cite quais as desvantagens da ferramenta para a compatibilização de projetos. 
De posse das respostas obtidas em cada questionário foi possível identificar o processo de compatibilização utilizado, bem como apontar os pontos positivos e negativos da gestão de projetos da Empresa A.

\subsection{Projetos Elaborados pela Empresa A}

Além dos questionários, obteve-se o acesso a 3 projetos de infraestrutura urbana elaborados pela Empresa A, que foram cedidos pelos seus gestores, sendo eles: projeto de drenagem de 25 ruas da cidade de Jaboatão do Guararapes, projeto de uma rua e revestimento de um canal do bairro de Areias Recife/PE e o projeto de urbanização e revestimento de um importante canal da cidade do Recife. De posse desses projetos, foi feita uma análise da compatibilização existente neles para detecção de possíveis incoerências. A análise foi feita por meio de uma leitura minuciosa dos projetos.

\section{Resultados e Discussões \\ 4.1 Questionário}

Segundo o Gestor 1, o processo de compatibilização de projetos é feito a partir da comunicação entre os responsáveis por cada disciplina, supervisionado pelo gerente que participa de todo processo para sintetizar todas as informações relacionadas ao projeto em questão. Segundo ele, toda a comunicação entre os envolvidos no processo é feita através de reuniões (formais e informais) e via e-mails. A Empresa A também possui uma diretoria de projeto que é responsável para fazer a interação entre as diversas áreas envolvidas no projeto, a fim de estabelecer uma boa relação entre elas.

Com relação aos prazos para execução dos projetos o Gestor 1 informou que os prazos são definidos pelo contratante e a Empresa A se encarrega de distribuí-los de forma eficiente para que o tempo disponível seja suficiente para elaborar os projetos e revisá-los antes da impressão e entrega aos clientes. Segundo ele, a Empresa A não utiliza ferramentas tecnológicas no processo de compatibilização de projetos e ele não deixou claro como é feito esse processo.

Para o Gestor 2, o processo de compatibilização de projetos é feito por meio da sobreposição de projetos no software Auto $C A D$, não sendo utilizado nenhuma ferramenta específica de compatibilização. Toda a 43 comunicação entre os envolvidos no processo é feita através de reuniões (formais e informais) e via emails. Segundo ele, o gerente de projeto realiza a sobreposição de todos os projetos para verificar se existem incompatibilidades entre eles, caso seja notada alguma incoerência esta é repassada aos colaboradores por meio de reuniões para que seja realizada as devidas correções.

Com relação aos prazos para execução dos projetos, o gestor 2 afirmou que estes são distribuídos respeitando-se a ordem sequencial dos projetos de infraestrutura urbana que, em suma, corresponde a pavimentação, drenagem e projetos complementares, dessa forma é possível evitar a quantidade de retrabalho decorrente das possíveis alterações na concepção do projeto. Segundo este gestor a tecnologia tem auxiliado na previsão (simulações por meio de softwares de modelagem e da Autodesk) de possíveis problemas de operação decorrentes das falhas de projetos, na compatibilização de projetos e no controle de prazos, garantindo assim a qualidade dos projetos.

De acordo com as respostas fornecidas pelos Gestores 1 e 2 foi possível identificar que a Empresa A utiliza um método tradicional para compatibilização de projetos, que é o método da sobreposição de layers. Sabe-se que este método pode acarretar em concepções errôneas e como consequência pode gerar um custo elevado nas fases do processo como um todo, afetando diretamente o cronograma e o orçamento final da obra. O uso de uma plataforma específica de compatibilização de projetos como a plataforma BIM, por exemplo, proporciona um ganho de produtividade no processo, além de outras vantagens, como citado por BRANDÃO (2014).

Como ponto positivo da Empresa A destaca-se a comunicação entre todas as etapas envolvidas no processo de produção. Os dois gestores entrevistados deixaram claro que esta comunicação e a interação entre os profissionais é indispensável para o bom funcionamento da empresa, o que pode refletir na qualidade dos produtos finais. Além disso, pode-se destacar os prazos para execução dos projetos que obedecem uma sequência estabelecida previamente a ponto de garantir que a entrega dos projetos aos clientes seja realizada após uma revisão geral, diminuindo assim os riscos de projetos incompatíveis. 


\subsection{Projetos Elaborados pela Empresa A}

$\mathrm{Na}$ análise dos projetos cedidos pela empresa A foi possível identificar algumas incompatibilizações, o que confirma a deficiência do método de compatibilização tradicional utilizado pela empresa. A Figura 3 mostra uma falha no projeto de drenagem de 25 ruas da cidade de Jaboatão dos Guararapes. O projeto geométrico deveria ter considerado a micro drenagem, pois a seção transversal da rua em questão foi dimensionada com duas quedas transversais conforme Figura 4. O template da Rua deveria ser projetado com apenas uma queda para o canal conforme Figura 5.

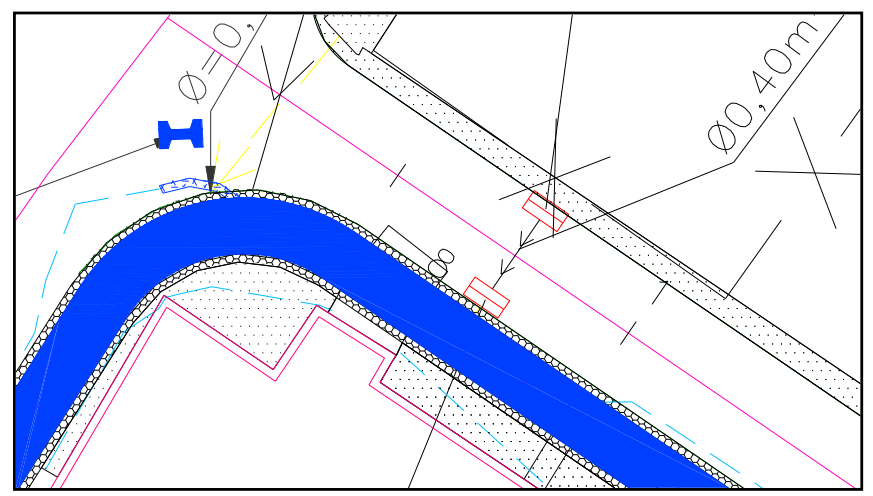

Figura 3: Projeto de Drenagem.

Fonte: Cedido pela Empresa A (2015).

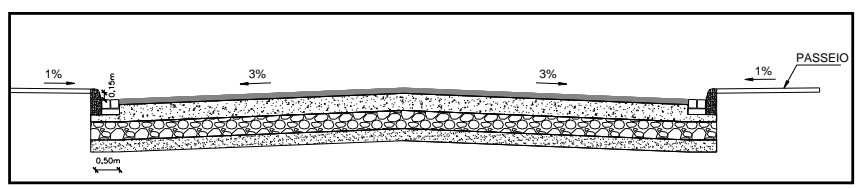

Figura 4: Seção tipo com declividade transversal para os dois lados.

Fonte: Cedido pela Empresa A (2015).

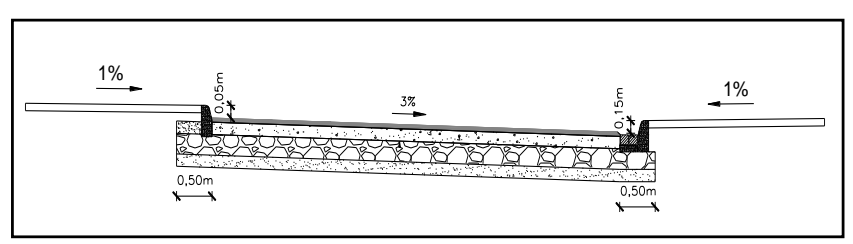

Figura 5: Seção tipo com declividade transversal um único lado.

Fonte: Cedido pela Empresa A (2015).

As Figuras 6 e 7 mostram um projeto de urbanização e revestimento de um importante canal da cidade do Recife. O projeto de iluminação foi elaborado sem a devida checagem com os demais projetos (drenagem e acessibilidade), logo observase inúmeras caixas de drenagem locadas nos mesmo lugares que os postes. Também se vê a existência de alguns postes de iluminação no centro das rampas de acessibilidade, deixando clara a incompatibilidade.

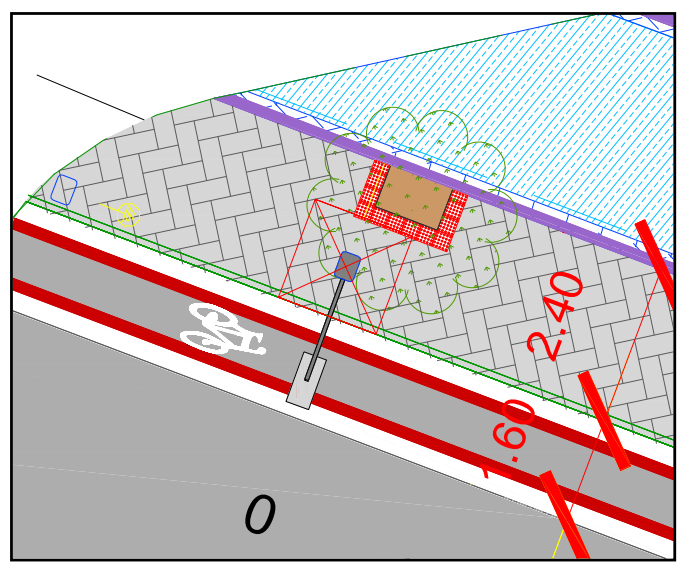

Figura 6: Incompatibilização do projeto de drenagem e iluminação.

Fonte: Cedido pela Empresa A (2015).

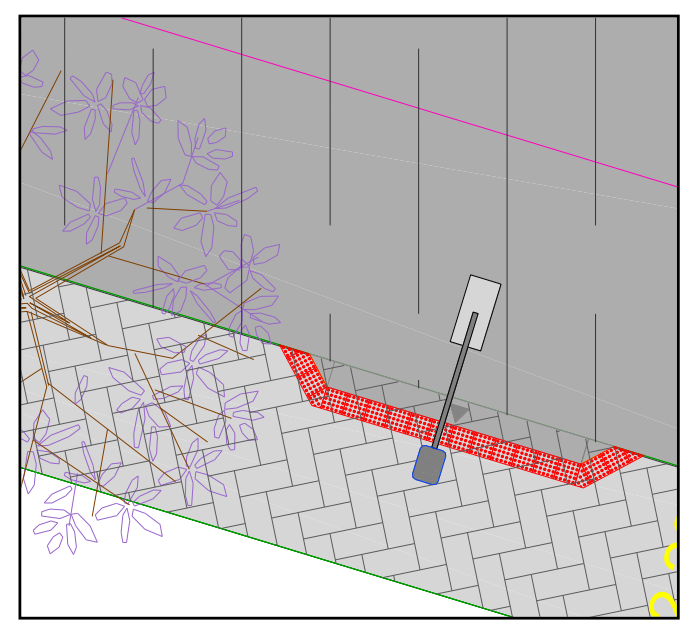

Figura 7: Incompatibilização do projeto de acessibilidade e iluminação.

Fonte: Cedido pela Empresa A (2015).

Foi analisado outro projeto do bairro de Areias onde será executada toda a infraestrutura urbana de uma rua além do revestimento do canal. Um dos projetos que compõem o escopo era o projeto urbanístico (Figura 8).

A fim de evitar ação de invasão dos moradores numa área livre entre as ruas projetadas, o arquiteto projetou uma praça. Assim o projeto foi elaborado com um desnível de $0,30 \mathrm{~m}$, e não foi atribuído a drenagem necessária para escoar a água advinda das chuvas (Figura 9).

DOI: $10.25286 /$ repa.v5i3.951 


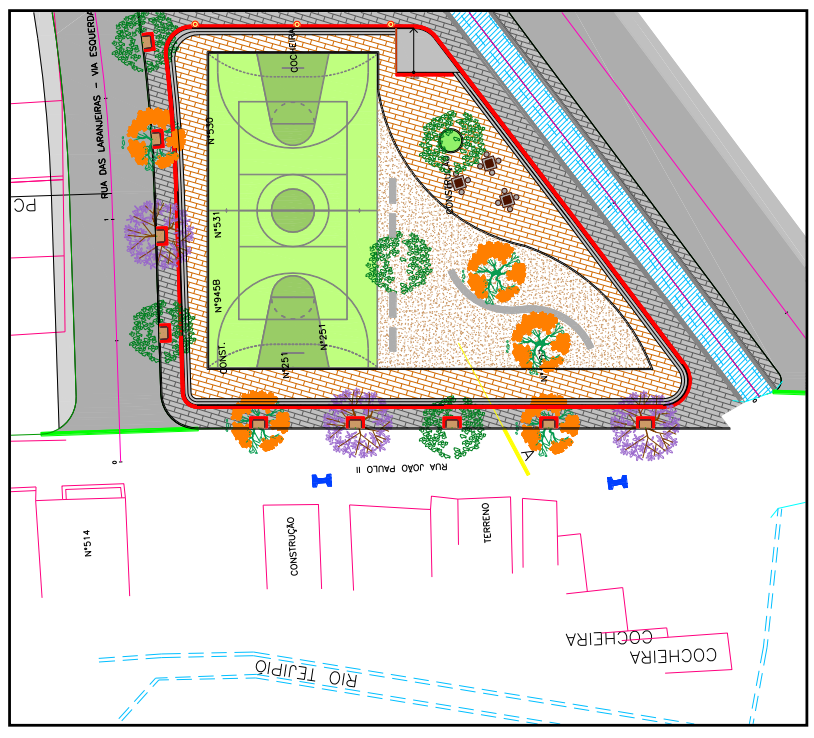

Figura 8: Projeto urbanístico da praça.

Fonte: Cedido pela Empresa A (2015).

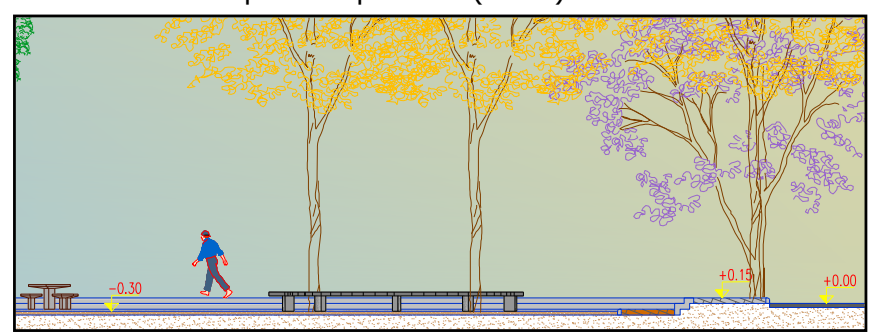

Figura 9: Seção transversal da praça projetada.

Fonte: Cedido pela Empresa A (2015).

\subsection{Soluções Propostas}

Face ao exposto observa-se que a Empresa A apesar de estar há 20 anos no mercado ainda oferece resistência em adaptar-se as mudanças do setor. Tendo em vista a análise dos projetos fornecidos pela empresa é possível perceber que o número de incompatibilidades é frequente, com isso tem-se perda de produtividade causando atrasos dos prazos, e como consequência pode gerar insatisfações dos clientes.

O Quadro 1 mostra as soluções cabíveis para as incompatibilidades identificadas nos projetos fornecidos pela Empresa $A$ e as possíveis consequências, caso não sejam efetuadas as compatibilizações.

Como a licitação é concebida pelo menor preço, a cotação do projeto é baseada em estimativas que, na maioria das vezes, não condiz com a realidade, isso acarreta no desenvolvimento de um projeto de baixa qualidade e como consequências listam-se as incompatibilizações e a má execução. Por isso, é importante que as licitações visem a qualidade do projeto e não o menor custo.

Quadro 1: Soluções para as incompatibilidades encontradas.

\begin{tabular}{|c|c|c|c|c|}
\hline Projeto & $\begin{array}{c}\text { Disc. } \\
\text { Envolvid } \\
a\end{array}$ & $\begin{array}{c}\text { Problema } \\
\text { s }\end{array}$ & $\begin{array}{c}\text { Soluçã } \\
\text { o }\end{array}$ & $\begin{array}{c}\text { Consequê } \\
\text { ncia }\end{array}$ \\
\hline $\begin{array}{l}\text { Infraestrutu } \\
\text { ra de } 25 \\
\text { Ruas em } \\
\text { Jaboatão } \\
\text { dos } \\
\text { Guararapes }\end{array}$ & $\begin{array}{l}\text { Geométrico } \\
\text { Drenagem }\end{array}$ & $\begin{array}{l}\text { Incluíram } \\
\text { dispositivos } \\
\text { de } \\
\text { drenagem } \\
\text { sem } \\
\text { necessidade } \\
\text {. }\end{array}$ & $\begin{array}{l}\text { Projetar a } \\
\text { seção } \\
\text { transvers } \\
\text { al da Rua } \\
\text { com uma } \\
\text { Queda } \\
\text { para o } \\
\text { canal. }\end{array}$ & $\begin{array}{l}\text { Aumento no } \\
\text { valor do } \\
\text { orçamento. } \\
\text { Atraso no } \\
\text { cronograma } \\
\text { da entrega } \\
\text { do projeto. }\end{array}$ \\
\hline $\begin{array}{l}\text { Urbanização } \\
\text { de canal em } \\
\text { Recife }\end{array}$ & $\begin{array}{l}\text { Iluminação } \\
\text { Acessibilida } \\
\text { de } \\
\text { Drenagem }\end{array}$ & $\begin{array}{l}\text { Poste locado } \\
\text { em cima da } \\
\text { caixa } \\
\text { coletora de } \\
\text { drenagem. } \\
\text { Poste locado } \\
\text { no centro da } \\
\text { rampa de } \\
\text { acessibilidad } \\
\text { e }\end{array}$ & $\begin{array}{l}\text { Deslocar } \\
\text { ou retirar } \\
\text { os postes } \\
\text { do local }\end{array}$ & $\begin{array}{l}\text { Qualidade } \\
\text { baixa no } \\
\text { produto final. } \\
\text { Atraso no } \\
\text { cronograma } \\
\text { de entrega } \\
\text { devido as } \\
\text { revisões. }\end{array}$ \\
\hline $\begin{array}{l}\text { Infraestrutu } \\
\text { ra de Rua } \\
\text { no Bairro } \\
\text { em Areias }\end{array}$ & $\begin{array}{l}\text { Urbanismo } \\
\text { Drenagem }\end{array}$ & $\begin{array}{l}\text { Falta de } \\
\text { drenagem } \\
\text { na praça } \\
\text { projetada. }\end{array}$ & $\begin{array}{l}\text { Projetar } \\
\text { uma } \\
\text { canaleta } \\
\text { no centro } \\
\text { da praça } \\
\text { com } \\
\text { declividad } \\
\text { es } \\
\text { direcione } \\
\text { m a água. }\end{array}$ & $\begin{array}{l}\text { Qualidade } \\
\text { baixa no } \\
\text { produto final. } \\
\text { Atraso no } \\
\text { cronograma } \\
\text { de entrega } \\
\text { devido a } \\
\text { revisões. }\end{array}$ \\
\hline
\end{tabular}

Fonte: Os autores

Vale destacar que a vistoria na área onde será executado o projeto deve ser realizada antecedendo a concorrência da licitação, assim possibilitaria a elaboração de um projeto mais próximo da realidade.

O fluxo de dados muitas vezes não se dá de maneira clara, o que torna o processo ainda mais vulnerável. Além disso, se observa a má gestão, visto que vários projetos são elaborados simultaneamente, e assim sobrecarrega os projetistas que acabam desconsiderando a etapa de compatibilização. Sugere-se estabelecer um modelo mais específico de trabalho para que a elaboração de um projeto não interfira na fase da elaboração de outro.

Os prazos muitos curtos estabelecidos pelos clientes é outro fator preponderante, que por não entenderem como se dá todo o processo da gestão de projetos acabam exigindo da empresa prazos muito curtos, com isso, a qualidade do projeto é afetada, pois nem sempre é possível revisar os projetos antes da impressão, bem como o processo de 
compatibilização é desconsiderado. É necessário que a Empresa $A$ conscientize os seus clientes do processo da gestão de projetos adotado pela empresa, através de reuniões formais.

A falta de organização na distribuição da equipe responsável pelo projeto, acarreta no aumento do tempo da elaboração de alguns projetos, pois quando a equipe é determinada o prazo já está comprometido. É importante que a equipe responsável pelo projeto seja determinada antes da aceitação da licitação, pois quando esta for estabelecida a equipe já deverá estar definida para iniciar os trabalhos, com isso o tempo será otimizado.

\section{Conclusões}

Face ao exposto, conclui-se que a gestão de projetos é um processo complexo, sendo necessário observar atentamente todas as etapas envolvidas na elaboração dos projetos a fim de compatibilizá-los. A comunicação entre todas as etapas envolvidas na elaboração de projetos é fundamental para o bom andamento da empresa. Visar a qualidade do projeto e não o menor preço na escolha da licitação é um fator decisivo para a qualidade final do produto. Também é importante a conscientização dos clientes na definição dos prazos e que a gestão da empresa esteja envolvida em todas as etapas da elaboração dos projetos, a fim de se verificar possíveis equívocos e corrigi-los com antecedência.

\section{Referências}

[1] GRAZIANO, F. P. Compatibilização de Projetos. Instituto de Pesquisa Tecnológica - IPT (Mestrado Profissionalizante), São Paulo, 2003.

[2] PICCHI, F. A. Entrevista. Revista Téchne, São Paulo, mar. / abr. 1993.

[3] MELHADO, S. B. et al.. Coordenação de projetos de edificações. São Paulo. O Nome da Rosa, 2005.

[4] OliveirA, O. J.; MELHADO, S. B. Como Administrar Empresas de Projeto de Arquitetura e Engenharia Civil. São Paulo: Pini, 2006. 